\title{
PATENT DUCTUS ARTERIOSUS
}

\section{A FOLLOW-UP STUDY OF 73 CASES}

BY

\author{
J. A. $\mathrm{COSH}$
}

From the University of Bristol and the Bristol Royal Infirmary

Received December 22, 1955

The best known studies of the eventual effects of patency of the ductus arteriosus are based upon autopsy results. They suggest a high incidence of serious complications such as bacterial endocarditis and congestive heart failure. Table I summarizes the average age at death, and the incidence rates of bacterial endocarditis and congestive heart failure in three published series. Maude Abbott's (1937) survey of 92 cases included 20 who died under 5 years of age, and 16 who died of causes not directly attributable to the patent ductus. Keys and Shapiro (1943) calculated that, at 17 years of age, the normal expectation of life was halved if the ductus were patent. Commenting on these figures, Brown (1950) points out that " our ideas are mainly based on post-mortem cases and take little account of the living. ... The adult case of patent ductus is a rare visitor to the clinic and the condition appears to be equally rare on post-mortem examination. . . . There must be spontaneous closure of the ductus more often than is generally realized, or cases are missed when failure supervenes and the characteristic physical signs disappear."

TABLE I

Patent Ductus Arteriosus-Necropsy Findings

\begin{tabular}{c|c|c|c|c}
\hline Authors & No. of cases & $\begin{array}{c}\text { Average age at } \\
\text { death (in years) }\end{array}$ & $\begin{array}{c}\text { Deaths from } \\
\text { subacute bacterial } \\
\text { endocarditis }\end{array}$ & $\begin{array}{c}\text { Deaths from } \\
\text { heart failure }\end{array}$ \\
\hline Maude Abbott, 1937 .... & 92 & 24 & $\begin{array}{c}27 \\
(29 \%)\end{array}$ & $\begin{array}{c}24 \\
(26 \%)\end{array}$ \\
\hline $\begin{array}{l}\text { Bulloek et al., 1939 (excluding } \\
\text { children under 4 years) }\end{array}$ & 80 & 29 & $\begin{array}{c}42 \\
(53 \%)\end{array}$ & $\begin{array}{c}18 \\
(23 \%)\end{array}$ \\
\hline $\begin{array}{l}\text { Keys and Shapiro, 1943 (ex- } \\
\text { cluding children under 17 } \\
\text { years) }\end{array}$ & 60 & 36 & $\begin{array}{c}25 \\
(42 \%)\end{array}$ & $\begin{array}{c}17 \\
(28 \%)\end{array}$ \\
\hline
\end{tabular}

For contrast with studies based upon autopsy results there are a few reports on the progress of living patients with patent ductus arteriosus. Wilson and Lubschez (1942) followed 38 children; one died suddenly from an unknown cause, but the remainder did well and were free from complications; few, however, were followed into adult life. Welti and Koerperich (1948) traced 41 out of 54 patients; 7 had died, and the age of the 34 survivors ranged up to 53 years; 14 were women who had borne children, three having had three children each; all the survivors were able to lead reasonably active lives, but in general had some limitation of physical effort; and 24 had dyspnœa and 21 cardiac enlargement. Benn (1947) reported on the progress of 46 patients, mostly children, contrasting the freedom from disability in 30 who had been diagnosed on routine school medical examination with 16 referred to hospital from other sources, 5 of whom developed bacterial endocarditis. 
Campbell (1955), reviewing 160 cases of patent ductus, found the majority of younger patients well and symptom-free, but those in the fourth decade or older tending to develop dyspnœa, cardiac enlargement, or failure. Deterioration in middle or later life was also mentioned by Gross (1952) in his report on 525 cases coming to surgery. To some extent these series must consist of selected cases, many being referred for an opinion with surgery in view.

Surveys based upon living patients suggest, therefore, that the prognosis with patency of the ductus is not as bad as autopsy studies indicate.

\section{The Present Study}

An account follows of the 73 patients with simple patency of the ductus arteriosus referred to the clinics or wards of the medical unit at Bristol in the past 30 years, under the care of the late Dr. Carey F. Coombs or Professor C. Bruce Perry. In all the diagnosis was made clinically on the presence of the characteristic murmur, and in none did it appear that any other lesion was present. The correctness of the clinical diagnosis was borne out by the finding of a patent ductus in the 28 coming to operation, and in the 5 coming to autopsy; one of the latter, however, was found to have a ventricular septal defect also. Included in this series are Benn's 46 cases, and the complications reported by him appear also in the inclusive survey made here. All surviving patients have been examined by the author except four who could not be traced, five who live at a distance but on whom current medical reports are available, and one who is known to be well but refuses to attend for examination.

The present state of the 73 may be summarized as follows: surviving with ductus not ligated, 34; surviving with ductus ligated, 28; died, 7; and follow-up incomplete, 4 cases.

Sex Incidence. Fifty-three were female and 20 male, giving a female preponderance of $2 \cdot 7$ to 1 , similar to that usually found.

\section{Progress of Patients}

In Relation to Source of Patients. The 73 patients have been divided into 4 groups according to the manner in which they were referred to hospital. Group I consists of 33 patients originally sent up to the children's heart clinic after discovery of a murmur on routine school medical examination. Their age when first seen averaged 7 years, and 21 years when last seen or when the ductus was ligated. Only 3 of the 33 had symptoms, two having dyspnœa and one a chest infection. Twentyone remain well without surgery, and of these four have lost their continuous murmurs; seven had the ductus ligated, of whom two had recently been cured of bacterial endocarditis; one other developed bacterial endocarditis and died; one boy died of diphtheria; and three were lost to follow-up.

In Group II are 20 patients referred to a general out-patient clinic from practitioners in or near the city; their age on first attendance averaged 13 years, and 21 when last seen or when the ductus was ligated. Fifteen, including three who were pregnant, had no symptoms; of the five with symptoms, two had dyspnœa, two had chest infections, and one palpitations from sinus tachycardia. Ten remain well without surgery, eight had the ductus ligated, one died of pulmonary embolism, and one was lost to follow-up.

In Group III are 8 patients who first came to hospital as direct admissions. Their ages averaged 14 years initially, and 23 when last seen or when the ductus was ligated. Three came with bacterial endocarditis, of which they died; three were children with respiratory infections. One was admitted for investigation with tachycardia: some years later her condition deteriorated, and she finally died in congestive failure. The eighth came in for investigation of vomiting; she is now well, although she has some dyspnœa, 35 years later. Of the 8 , four died of causes attributable to the ductus, three survive without surgery, and one has had the ductus ligated.

Group IV consists of 12 cases admitted to the medical wards from other hospitals specifically for surgery. Seven were symptom-free; one was a girl of 4 years with recurrent chest infections and 
cardiac enlargement; the remaining four had dyspnœa, the most severe being a miner of 24 years who had recently developed congestive failure with auricular fibrillation. In all 12, the ductus was ligated.

As pointed out by Benn, Goup I is probably a truly representative group of unselected patients with patent ductus of 5 or more years of age, being composed of cases found on routine medical examination of the great majority of Bristol school children. On the other hand, Groups II and III together represent cases normally referred to hospitals and clinics. Of the 33 in Group I, 30 (91\%) were initially symptom-free, in $7(21 \%)$ the ductus was ligated, and $21(63 \%)$ survive without ligation. Of the 28 in Groups II and III, $15(54 \%)$ were initially symptom-free, in $9(32 \%)$ the ductus was ligated, and $13(46 \%)$ survive without ligation. In each class three patients developed bacterial endocarditis. The two classes differ in that the initial average age in Group I was 7 years, and in Groups II+III 14 years; but Group I was followed for 14 years on the average, with the ductus patent, and Groups II+III for 8 years only.

It appears, then, that in a representative and unselected group of 33 patients with patent ductus, the incidence of symptoms was lower, and the subsequent course rather more favourable, than among 28 patients referred to hospital in the usual way. The incidence of bacterial endocarditis was similar in the two classes.

Deaths. Seven among the 69 traced patients have died. The causes of death were bacterial endocarditis in four, pulmonary embolism in one, congestive heart failure in one, and diphtheria in one. The patient dying from pulmonary embolism was aged 39 years, and is the subject of a separate report (Cosh, 1956). The patient with congestive failure died at home, aged 33, and no autopsy was performed; at the age of 16 she was known to have cardiac enlargement, a systolic thrill, and the cardiogram of left ventricular hypertrophy.

Bacterial Endocarditis. Six patients in the series developed bacterial endocarditis. Four died before penicillin was introduced, and the two who survived were both infected with Streptococcus viridans and recovered after the usual treatment; in each the ductus was ligated a few weeks later. The ages at which bacterial endocarditis arose were $11,21,25$, and 36 years in those who died, and 9 and 23 years in those who recovered, giving an average of 21 years. This compares with average ages of 24 years in Bullock's series and 27 years in Keys and Shapiro's series.

The incidence of 6 cases among 69, or 9 per cent, is far lower than the rates quoted in Table I. The difference must be attributed to the facts that in studies based upon published autopsied cases, the incidence of infection is exaggerated; that survivors with patent ductus in this series continue to run the risk of infection; and that present-day risks are lessened by the prophylactic use of penicillin.

In all, the 73 patients reviewed here lived a total of 1451 years up to the time of their last examination or to ligation of the ductus. As 6 patients became infected, this represents an infection rate of 0.4 per cent per annum. At this rate, among the 34 patients surviving without surgery, one case of infection might be expected in every 7 years.

Progress of Patients without Operation. Ten male and 24 female patients have not been submitted to operation. Their average age is 26 years, and their ages are distributed as follows:

$\begin{array}{rllllr}5 \text { to } 9 \text { years } & \ldots & \ldots & \ldots & 1 \\ 10 \text { to } 19 & , & \ldots & \ldots & \ldots & 10 \\ 20 \text { to } 29 & , & \ldots & \ldots & \ldots & 10 \\ 30 \text { to } 39 & , & \ldots & \ldots & \ldots & 10 \\ 45 \text { to } 56 & , & \ldots & \ldots & \ldots & 3\end{array}$

The great majority lead normal lives. Seven are aware of some dyspnœa or fatigue on exertion, but are not appreciably handicapped by this. Of the 10 males, two are normally active schoolboys, and eight are men in various occupations, two having served in the army. Of the 24 females, five are schoolgirls, nine are unmarried women working or studying, and ten are married, eight of these having borne children. 
Pregnancy. Between them the 8 mothers have borne 23 children. One has had ten children, two have had three children each, two have had two each, and three have had one each. Some women were aware of fatigue or dyspnœa towards the end of pregnancy, but in one only was admission to hospital advised before term. Delivery occurred normally in all.

Among the seven patients who died, two had borne children. One woman, who died at the age of 27 years from bacterial endocarditis, had had two normal deliveries. The other, who died aged 39 from pulmonary embolism, had had one child without difficulty, but her second pregnancy was terminated by hysterotomy at the fourth month, as she suffered from dyspnœa and fatigue and had considerable cardiac enlargement.

On clinical grounds it is unlikely that the ductus is a wide one in any of the eight surviving women who have borne children. Nor have they signs suggesting pulmonary hypertension. Three have slight cardiac enlargement, with cardio-thoracic ratios of 50-55 per cent, and one other has left ventricular hypertrophy on the electrocardiogram. Other reports of successful pregnancy in the presence of a patent ductus are given by Bramwell and Longson (1938), Mendelson and Pardee (1941), Gilchrist (1945), and Kernohan (1953). In general it is clear that pregnancy is well tolerated in the presence of a patent ductus of small or moderate size.

Changes Noted in the Murmur and Thrill. In 60 of the 73 cases, the murmur was on all occasions typical in character and situation, agreeing with the description of Gibson (1906). Seven children, when first seen, had a systolic murmur only in the pulmonary area, and a continuous murmur was noted later. The ages at which the continuous murmur was first heard were: $3,3,4,4,5$, 5, and 6 years. In five of these seven the initial systolic murmur was accompanied by a thrill, which could still be felt, in systole only, after the murmur had become continuous. These 5 children were later chosen for operation on the grounds of poor growth, dyspnœa, or cardiac enlargement.

In four patients the continuous murmur has disappeared; two of these have already been mentioned by Benn (1947). All four are symptom-free, with no enlargement of the heart on X-ray, normal blood pressures, and normal electrocardiograms. Further details are as follows.

$J$. C. A girl was examined annually between 8 and 12 years of age; on each occasion a continuous murmur was heard; there was no thrill. When 15 she had pulmonary tubercle with positive sputum. Examination at ages $15,21,25,31$, and 34 revealed a faint systolic murmur only.

G. I. A boy, said to have congenital heart disease at one year of age, was found to have a continuous murmur at 10 years of age. At 23 he was serving as an able seaman with the Royal Navy: a soft basal systolic murmur only was heard. At ages 27 and 33, he was well and had no murmurs.

$B$. G. A girl was seen periodically between 5 and 16 years of age, a continuous murmur being heard each time. When she was 5 , there was a systolic thrill at the pulmonary area, but not thereafter. When 23 , she was well and working, and there were no murmurs.

L. S. A boy had a pulmonary systolic murmur when 4 , and a continuous murmur at 5 and 8 years old. When 29, he was seen by Dr. J. W. Brown, who found no abnormal physical signs.

Disappearance of the continuous murmur has been described when congestive failure develops (Campbell and Hudson, 1952), and the murmur is absent with severe pulmonary hypertension (Cosh, 1953; Dammann et al., 1953; Yu et al., 1954; Lukas et al., 1954; and Whitaker et al., 1955), Neither of these conditions apply to the four cases described here, particularly as signs of pulmonary hypertension and right ventricular hypertrophy were absent. It seems more likely that the loss of the murmur may be explained by shrinkage of the ductus or its actual closure. Apparent delayed closure of the ductus has been noted by Brown (1950) in five cases, by Shapiro and Keys (1943) in two, and by Gilchrist (1945) in one.

A thrill at the pulmonary area was felt throughout the follow-up period in 35 patients, and was consistently absent in 24 . It is of some interest to compare the later course of these two groups. Of the 35 with a thrill, 22 were chosen for operation on account of symptoms, poor growth, or cardiac enlargement; 5 others died. Of the 24 with no thrill, only 5 came to surgery, and these were symptom-free without cardiac enlargement ; two died, of bacterial endocarditis. These figures suggest that the presence of a thrill is a useful guide to the prognosis, presumably because it signifies the presence of a wide ductus. 


\section{RADIOLOGY}

Radiographs of 65 patients were available, in the majority covering periods of several years, and estimates of heart size were made from the cardiothoracic ratio. Thirty-one patients had ratios under 50 per cent; in 21 there was slight enlargement (ratio 50-54\%), in 8 moderate enlargement (ratio 55-59\%) and in 5 much enlargement (ratio over 60\%). No patient during the follow-up period had an increasing heart size according to this grading, although it decreased in some. Apart from the reduction in cardio-thoracic ratio seen in the first five years of life, a reduction was noted to have occurred spontaneously in 4 , and to have followed ligation of the ductus in 9 patients.

The size of the main pulmonary artery was estimated by measurement of the " pulmonary artery index" (Evans, 1943). This is the distance from the junction of the superior vena cava and the right atrium on the right heart border, to the most prominent point on the outline of the pulmonary artery on the left heart border. It normally measures less than $7 \mathrm{~cm}$ in the adult. In 41 out of 65 patients this index was under $7 \mathrm{~cm}$; in 17 it was $7-8 \mathrm{~cm}$, and in 7 over $8 \mathrm{~cm}$. An increasing index was naturally found in children up to adolescence, but only one adult had a progressive increase in size of the pulmonary artery (Cosh, 1956). No patient had a measureable decrease in the size of the pulmonary artery after ligation of the ductus. Only in two patients with gross dilatation of the pulmonary artery (index over $9 \mathrm{~cm}$ ) was there any obvious correlation between the size of the pulmonary artery and the severity of the patient's symptoms, the size of the heart, or the degree of vascularity of the lung fields.

Fluoroscopy was carried out on 45 patients. In 5 there was no visible pulsation in the pulmonary arteries; in 21 the pulsation was minor and only in the main branches; in 15 it was moderate or brisk; and in 4 it was striking, with a hilar dance. Some correlation was found between the degree of pulsation seen and the systemic pulse pressure; in 11 of the $19(58 \%)$ with moderate or striking pulsation of the main pulmonary arteries the systemic pulse pressure was over $50 \mathrm{~mm} / \mathrm{Hg}$. In only 6 of the remaining 26 patients $(23 \%)$ was the systemic pulse pressure as large as this.

Cardiac enlargement was not found more frequently among the older patients, for, of the 13 aged 30 years or more, 8 had cardiothoracic ratios below 50 per cent. In 9 of this group there was dilatation of the aortic arch and increased prominence of the aortic knuckle; 4 of these had calcification in the aortic wall or in the region of the ductus, best revealed by tomography in the lateral position.

\section{The Electrocardiogram}

Electrocardiograms were available in 69 cases, 54 having præcordial leads and 15 limb leads only. The majority were normal.

Left axis deviation (less than $-20^{\circ}$ ) was found in 6; in 4 of these præcordial leads were available, but only one showed left ventricular hypertrophy. Right axis deviation (over $+100^{\circ}$ ) occurred in 2 ; one was an asthmatic girl with a vertical heart, and the other a woman with pulmonary hypertension and right bundle-branch block.

Left ventricular hypertrophy with strain pattern (S-T depression and/or $\mathrm{T}$ inversion in leads I, aVL, or V 4, 5, or 6) was seen in 7 patients. Each had a systolic thrill. Four were seen in childhood, and were then underweight. The three adults were dyspnœic, and one died in congestive heart failure. The 6 survivors with left ventricular hypertrophy had enlarged hearts: in 5 the ductus has been ligated and they are well, and in the sixth it is still patent; she is 26 and has borne one child, and has no symptoms. She is the only patient in whom past records show the development of left ventricular hypertrophy; the first changes were seen at the age of 9 (see Fig. 1 and 3, E.W.).

Auricular fibrillation was seen twice. One man with pulmonary hypertension and a greatly enlarged heart spontaneously developed auricular fibrillation and congestive failure when he was 24: five months later the ductus was ligated, but fibrillation has persisted, without reduction in the size of the heart, and after two years he again developed heart failure, from which he has recovered. Co-existent rheumatic heart disease cannot be excluded. A similar patient, who continued to 


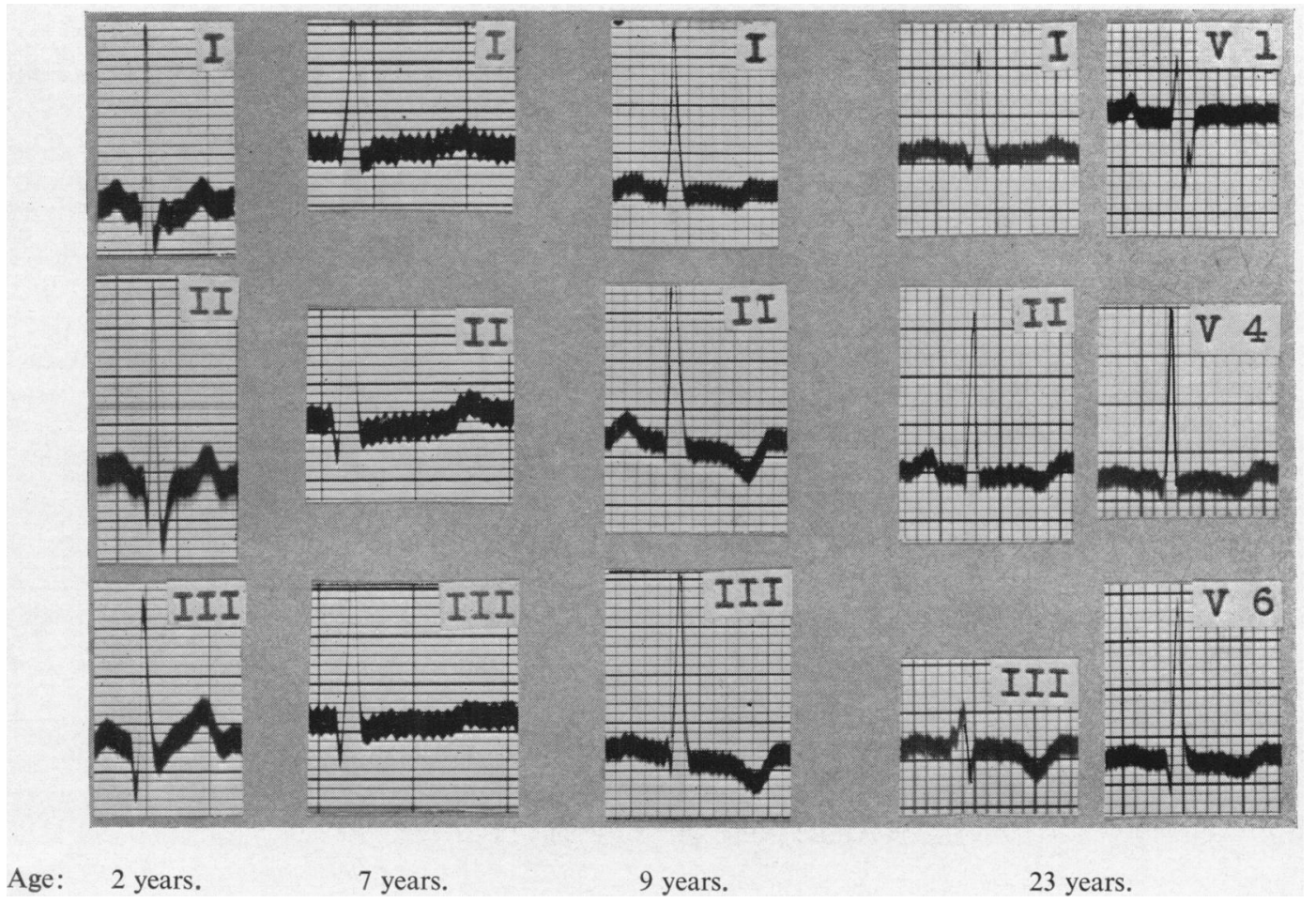

FIG. 1.-The development of electrocardiographic changes of left ventricular hypertrophy. Age 2, normal record. Age 7, T waves diminished in amplitude. Age 9, T waves biphasic in I, inverted in II and III. Age 23, the axis has changed from vertical towards horizontal; T remains inverted in II and III; V4 and V6 show tall $R$ and biphasic T waves.

show fibrillation and died suddenly four years after legation of the ductus, is described by Dry et al. (1948); autopsy showed no signs of rheumatic heart disease. The second case of auricular fibrillation was a man of 35 with pulmonary hypertension and a large heart, in whom arrhythmia followed ligation of the ductus; sinus rhythm returned two weeks later after quinidine.

Effect of Operation on the Electrocardiogram. Cardiograms were obtained before and after operation in 20 cases. There was no significant change in 14 of these, but the only two patients with $\mathrm{S}-\mathrm{T}$ depressions in lead I before operation both had normal records afterwards. Other changes noted were of a minor nature. Landtman (1954), reviewing cardiographic changes resulting from ligation of the ductus, reported that 18 of 25 patients with S-T depression in lead I associated with left ventircular hypertrophy lost this depression.

Effect of Age on the Electrocardiogram. Of the 13 patients aged over 30 years, 11 had completely normal 12-lead tracings, one had left ventricular hypertrophy, and one had right bundle-branch block. It appears that age alone has no particular influence on the electrocardiogram in the presence of a patent ductus.

Children's Weights. Sutcliffe and Canham (1950) have established the normal range of weights of English school children aged 5-17 years. From their figures for the percentile distribution of weights 6 groups may be defined, which for convenience may be named A to F (Fig. 3). A quarter of all normal children are in the upper two groups, A and B; half are in the middle groups, $\mathrm{C}$ and $\mathrm{D}$; and a quarter are in the lowest groups, $\mathrm{E}$ and $\mathrm{F}$. 


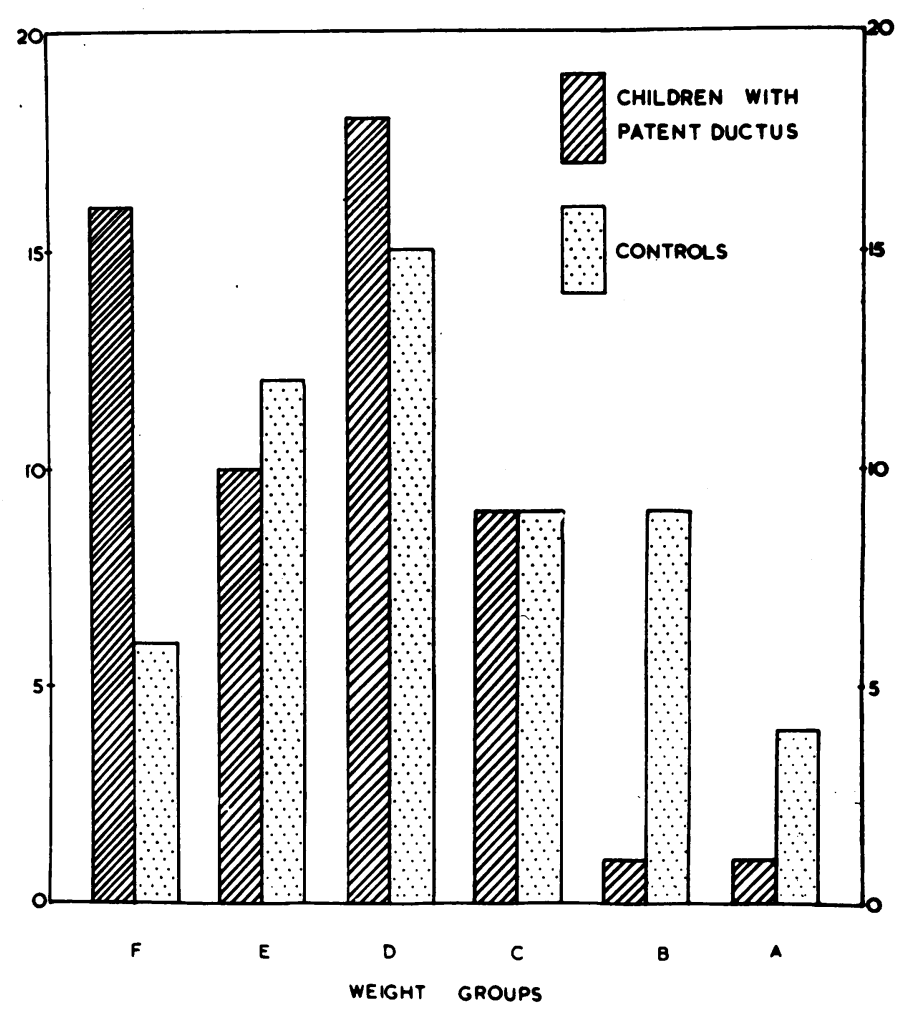

FIG. 2.-Distribution of weights of 55 children with patent ductus and of 55 individually-matched normal controls. They are shown in 6 weight groups, derived from the data of Sutcliffe and Canham (1950); $A$ is the heaviest group and $\mathrm{F}$ the lightest. Children with patent ductus tend to occupy the lower weight groups.

The weights of 55 children with patent ductus, with an average age of 8 years, were classified in these six groups. For comparison, a classification was also made of 55 normal Bristol school children, matched individually with the 55 patients by age and sex. Fig. 2 shows not only that children with patent ductus fall more often into the lower groups than the upper, but also that their distribution in these groups is different from that of the controls. This difference is statistically significant, and would arise by chance less often than once in a hundred times.

Many of the children with patent ductus were followed through their school years: 21 out of 30 remained in the same weight group as they grew older; 5 improved by one or two groups; and 4, though gaining in weight, declined by one or two groups.

The Effect of Operation on Weight. The effect of ligation of the ductus upon the weight curve was studied in 13 children, who were followed after operation for periods ranging from 1 to 5 years. All gained weight, but 9 remained in the same group as before operation, while 4 improved by one or two groups. Fig. 3 illustrates the progress of four girls, two of whom had the ductus ligated, and two not.

The gain in weight that followed ligation of the ductus was thus, in the majority, no more than might have been expected without ligation. Indeed, improvement in weight relative to the normal standards for a child's age and sex may even lag behind improvement as judged by other criteria; two girls were observed to remain in a low weight group after surgery, although their hearts diminished in size and S-T depressions in lead I were corrected. 


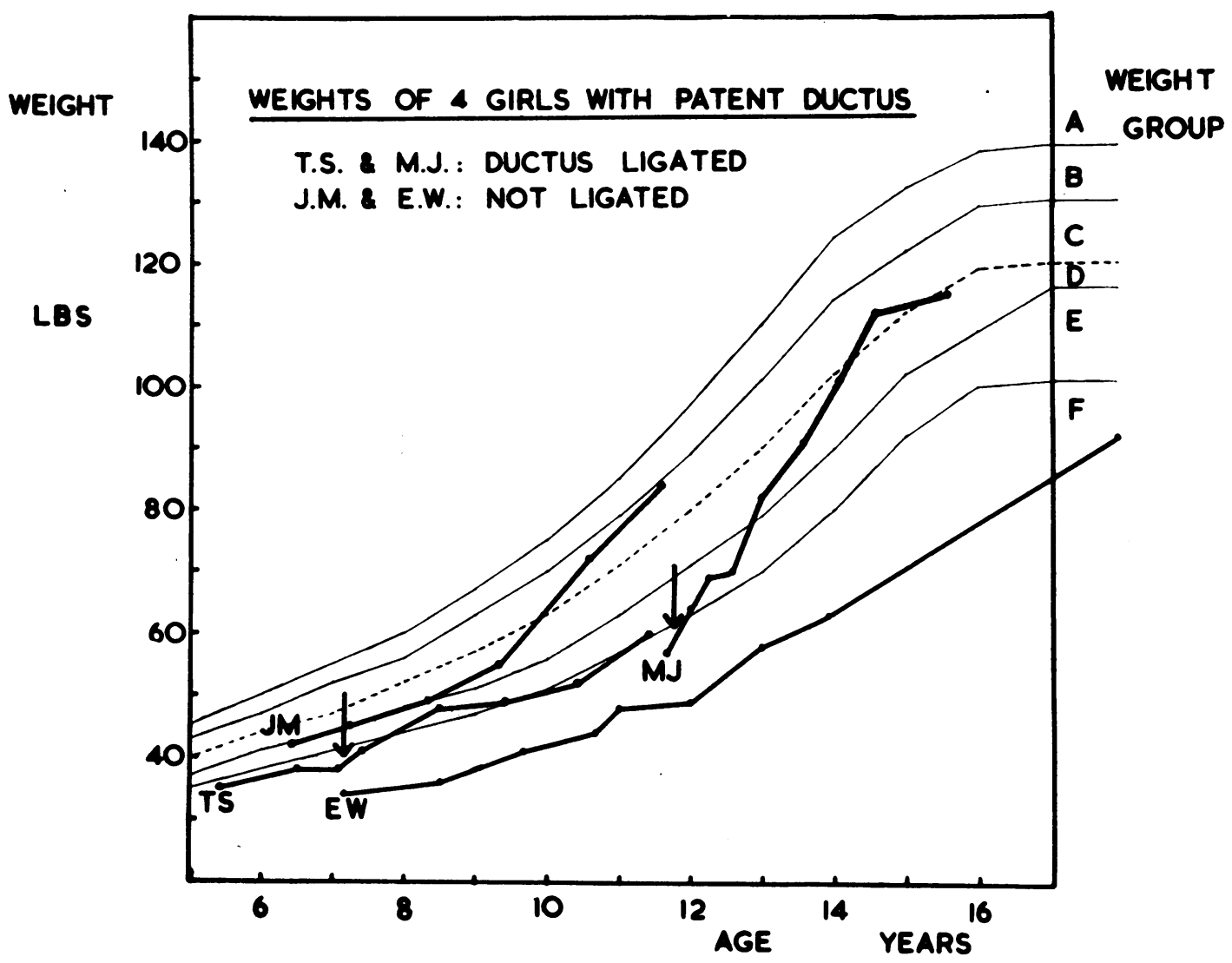

FIG. 3.-Examples of weight curves in 4 girls with patent ductus. The 5 background lines separate 6 weight groups, A to $F$, and the dotted line between groups $C$ and $D$ shows the median weight for girls. E. W. (see also Fig. 1) remained obviously under-weight, in group F throughout, but J. M.'s weight improved spontaneously as she grew older. The weight of T. S. remained low for her age, in spite of ligation, indicated by the arrow. M. J.'s weight improved dramatically after ligation.

Selection for Surgery. As already indicated, patients were selected for operation when it was clear that they had symptoms of dyspnœa or fatigue due to the presence of the patent ductus, or if they were significantly under-weight, or had enlarged hearts, or had had bacterial endocarditis. Exceptions were those in Group IV, who were referred from other centres specifically for surgery; all of these had the ductus ligated irrespective of symptoms. Operations were performed by Professor R. Milnes Walker or Mr. R. Belsey. There were no deaths and few post-operative complications (Cade, 1954). Recanalization has occurred in one.

\section{Discussion}

While this review shows an appreciable mortality and infection rate among patients with patent ductus, it suggests a much better prognosis than do those reports that are entirely based upon autopsy findings. It shows, too, a lower morbidity rate in unselected cases than among those usually referred to hospital. Other features are the general well-being of the adult patients, the occurrence of pregnancies and childbirth without complication, and the occasional apparent closure of the ductus in early adult life. 
Those patients who survive without operation are a selected group in that the worst cases have either died, or have had the ductus ligated, implying that the ductus is not widely patent in those who have not had surgical treatment. The first 21 cases in the series, however, all diagnosed before 1934, are unselected in that none have had the ductus ligated. Of these 21 , four have died, two of bacterial endocarditis, one of heart failure, and one of diphtheria; two cannot be traced; but the remaining 15 are well, and include the 4 who have lost their continuous murmurs.

Surgery is certainly indicated when the signs suggest that the ductus is a wide one, and wise when the ductus has recently been infected. If the ductus is small and causing no disability in an otherwise healthy child, surgery is justified, for the risks of ligation are now less than the small risks of leaving the ductus patent. But this survey suggests that in an adult with few or no symptoms, and little or no cardiac enlargement, the ductus may safely be left open as long as care is taken in preventing bacterial endocarditis. In such a patient there is no contra-indication to childbirth.

\section{SUMMARY}

Of 73 patients with patent ductus arteriosus known to one clinic over the past thirty years, 69 have been traced. Seven have died, of causes that are directly attributable to the ductus in five and indirectly in one. Six developed bacterial endocarditis, representing an incidence rate of 0.4 per cent per annum.

The ductus was ligated in 28 , the usual indications being dyspnœa, fatigue, poor physique in childhood, cardiac enlargement, or recent bacterial endocarditis.

The ductus was not ligated in 34, whose average age is now 26 years. None suffer serious restriction of activity, though 7 are aware of dyspnœea, and 8 have some cardiac enlargement. In 4 the continuous murmur has disappeared.

Twenty-one of the 35 patients with a thrill, and only 5 of the 24 without a thrill, were selected for operation.

Childbirth occurred 23 times in patients with the ductus patent, without difficulty or complication. Only one patient required termination of pregnancy with sterilization.

Children with patent ductus were significantly under-weight when compared with normal controls. Only 4 out of 13 showed a significant improvement in weight in the years following ligation of the ductus.

I wish to thank Professor C. Bruce Perry, who was in charge of these patients and suggested this survey, for his help and criticism. My thanks are also due to Dr. J. W. Brown for his report on one of the patients, to Dr. Gustav Herdan, Lecturer in Statistics, University of Bristol, for his analysis of the weight figures, and to Dr. A. L. Smallwood, Senior School Medical Officer, Bristol, for the weights of normal control children.

\section{REFERENCES}

Abbott, M. E. (1937). Nelson's Loose-leaf Medicine, Nelson, N.Y., 4, 266.

Benn, J. (1947). Brit. Heart J., 9, 283.

Bramwell, C., and Longson, E. A. (1938). Heart Disease and Pregnancy, O.U.P., London, p. 117.

Brown, J. W. (1950). Congenital Heart Disease. 2nd ed., Staples Press, Ltd., London.

Bullock, L. T., Jones, J. C., and Dolley, F. S. (1939). J. Pediat, 15, 786.

Cade, I. S. (1954). Brit. J. Surg., 42, 31.

Campbell, M. (1955). Brit. Heart J., 17, 511.

, and Hudson, R. (1952). Guy's Hosp. Rep., 101, 32.

Cosh, J. A. (1953). Brit. Heart J., 15, 423.

(1956). Brit. Heart J., 18, 417.

Dammann, J. F., Berthrong, M., and Bing, R. J. (1953). Bull. Johns Hopk. Hosp., $92,128$.

Dry, T. J., Harrington, S. W., and Edwards, J. E. (1948). Proc. Mayo Clin., 23, 267.

Evans, W. (1943). Brit. Heart J., 5, 205.

Gibson, G. A. (1906). Med. Press, 81 (NS), 572.

Gilchrist, A. R. (1945). Brit. Heart J., 7, 1.

Gross, R. E. (1952). Amer. J. Med., 12, 472.

Kernohan, R. J. (1953). Brit. med. J., 1, 978.

Keys, A., and Shapiro, M. J. (1943). Amer. Heart J., 25, 158. 
Landtman, B. (1954). Circulation (N.Y.), 10, 871.

Lukas, D. S., Araujo, J., and Steinberg, I. (1954). Amer. J. Med., 17, 298.

Mendelson, C. L., and Pardee, H. E. B. (1941). Amer. J. med. Sci., 202, 392.

Shapiro, M. J., and Keys, A. (1943). Amer. J. med. Sci., 206, 174.

Sutcliffe, A., and Canham, J. W. (1950). The Heights and Weights of Boys and Girls. John Murray, London. Welti, J-J., and Koerperich, G. (1948). Arch. Mal. Cour, 41, 428.

Whitaker, W., Heath, D., and Brown, J. W. (1955). Brit. Heart J., 17, 121.

Wilson, M. G., and Lubschez, R. (1942). J. Pediat., 21, 23.

Yu, P. N., Lovejoy, F. W., Joos, H. A., Nye, R. E., and Beatty, D. C. (1954). $\quad$ Amer. Heart J., $48,544$. 